\title{
LIBERTAD DE EXPRESIÓN E INTERÉS SUPERIOR DEL NIÑO, A PROPÓSITO DE LA SENTENCIA DE LA CORTE DE APELACIONES DE ANTOFAGASTA DE 6 DE MARZO DE 2009 Y CORTE SUPREMA DE 23 DE ABRIL DE 2009
}

\section{Domingo A. Lovera Parmo}

Profesor de Derecho Constitucional

Universidades Diego Portales y Adolfo Ibáñez

I

De acuerdo con la CDN,

"[e]n todas las medidas concernientes a los niños que tomen las instituciones públicas o privadas de bienestar social, los tribunales, las autoridades administrativas o los órganos legislativos, una consideración primordial a que se atenderá será el interés superior del niño".

Como se ha señalado reiteradamente, la CDN altera la condición (jurídica) del niño, quien deja de ser objeto de política, regulación y protección, para convertirse en sujeto de derecho, esto es, titular de derechos cuya protección niños, niñas y adolescentes pueden reclamar.

No puede negarse, en este sentido, que la CDN impactó nuestra legislación de familia, provocando cambios relevantes. Así, el antiguo artículo 36 de la Ley de Menores (ley
No 16.618, Diario Oficial, 8 de marzo de 1967), disponía:

"[e]l juez de letras de menores en todos los asuntos de que conozca apreciará la prueba en conciencia y, si fuere posible, deberá oír siempre al menor púber y al impúber, cuando lo estimare conveniente. Además de los informes que solicite a los asistentes sociales, podrá requerir informes médicos, psicológicos u otros que estimare necesarios".

Se trataba, qué duda cabe, de una facultad concedida al tribunal antes de que de una atribución de facultades legales al niño, y operaba sólo en la medida que el juez lo considerara posible, conviviendo, además, con otras disposiciones de clara orientación paternalista, como es el caso del artículo 234, inc. $3^{\circ}$ del Código Civil:

"Cuando sea necesario para el bienestar del hijo, los pa- 
dres podrán solicitar al tribunal que determine sobre la vida futura de aquel por el tiempo que estime más conveniente, el cual no podrá exceder del plazo que le falte para cumplir dieciocho años de edad"1.

Como CDN era (y es) mucho más exigente en este sentido, se introdujeron algunas reformas con el objetivo que adecuar la legislación nacional a los requerimientos que demandaba la nueva condición jurídica del niño ${ }^{2}$. Así, hoy, el artículo 242 del Código Civil dispone -desde 1998 (ley No 19.585, Diario Oficial, 26 de octubre de 1998)-:

"para adoptar sus resoluciones el juez atenderá, como

${ }^{1}$ Sobre este punto, Julio CORTÉs, "Acerca del principio del interés superior del niño", en Julio Cortes, Consuelo Contreras, Infancia y Derechos Humanos: discurso, realidad y perspectivas, Santiago, Corporación OPCIÓN 2001, pp. 78-9.

${ }^{2}$ En efecto, el Comité sobre Derechos del Niño ya había advertido al Estado de Chile sobre la necesidad de realizar "esfuerzos especiales en orden a armonizar completamente la legislación [nacional] existente con las provisiones de la Convención relativas a los principios generales, así como asegurar que el interés superior del niño, tal cual se establece en el artículo 3 de la Convención, sea la primera consideración en todas las acciones que conciernan a los niños, incluidas las llevadas adelante por el parlamento". Committee on the Rights of the Child: Chile, "Concluding Observations of the Committee on the Rights of the Child: Chile", CRC/C/15/add.22. (25 de abril de 1994). consideración primordial, el interés superior del hijo, y tendrá en cuenta sus opiniones en función de su edad y madurez".

La ley que crea los nuevos tribunales de familia, a su turno, y vigente desde 2005 , incorpora varias otras normas importantes en el sentido que venimos señalando. El artículo 16 inc. $1^{\circ}$ dispone -bajo el epígrafe "interés superior del niño"- que el objetivo de la ley es garantizar a los niños, niñas y adolescentes "el ejercicio y goce pleno y efectivos de sus derechos y garantías" ${ }^{3}$ El inc. $2^{\circ}$ añade que dicho interés, junto con el

"derecho a ser oído, son principios rectores que el juez de familia debe tener siempre como consideración principal en la resolución del asunto sometido a su conocimiento" .

Como se aprecia, en la regulación anterior a las reformas $-y$ anterior, digamos, al momento en que el Parlamento decide tomarse en serio la CDN- la participación e intervención del niño en los procedimientos que decidían su suerte judicial (y, en muchos casos, su suerte sencillamente), era una facultad discrecional del juez. La intervención ocurría, en el

${ }^{3}$ Ley No 19.968 (Diario Oficial, 30 de agosto de 2004).

${ }^{4}$ De acuerdo con la ley 19.968, el interés superior del niño será, también, principio rector del proceso de mediación. Art. 103 letra e). 
mejor de los casos, si el juez lo consideraba pertinente. Esto no quiere decir que antes no se protegieran sus derechos; sin embargo, esa tutela descansaba exclusivamente en lo que el Estado y los jueces, antes, y los padres de esos niños y niñas, después, opinaban que era una buena vida para ellos ${ }^{5}$. En la regulación vigente, en cambio, y a menos en el ámbito discursivo-legal, la condición de niño y adolescente ha variado, en línea con los mandatos de la CDN, siendo su interés, hoy, la consideración primordial a la que deben atender los jueces, por una parte, $y$ principio rector-junto a su derecho a ser oído-de los procedimientos de familia, por otra.

\section{II}

Las disposiciones del Derecho de Familia, entonces, establecen una relación -aunque, por cierto, vaga e imprecisa- con la CDN. Esa vaguedad e imprecisión, sugerida en un comienzo, sólo empeoraba las cosas. En efecto, parte importante de las primeras críticas que conoció el prin-

${ }^{5} \mathrm{La}$ Corte Europea de Derechos $\mathrm{Hu}-$ manos ha señalado que "en las consideraciones judiciales donde los derechos del artículo 8, de los padres y del niño, están comprometidos, los derechos del niño deben recibir la consideración superior. Si es necesaria cualquier ponderación de intereses, el interés del niño debe prevalecer". CORTE Europea de Derechos Humanos, "Yousef v The Netherlands", in Family Law Reports, London, 2003, p. 210. cipio del interés superior del niño estaban encaminadas a enrostrarle a la CDN la amplitud con que establecía el principio, el cual, lejos de servir de límite a la discrecionalidad de las autoridades, jueces incluidos ${ }^{6}$, abría campo fértil para ella. Prácticamente, cualquier decisión podía terminar justificándose en el interés de los niños y adolescentes involucrados, cuestión que, en el contexto latinoamericano -que consideraba a los niños como un objeto de protección- era en especial cierta ${ }^{7}$. Tal era la situación de los sistemas de responsabilidad penal, por ejemplo, que bajo la promesa de protección de niños y adolescentes los privaba de las garantías de un debido proceso ${ }^{8}$ o de decisiones adoptadas en resguardo del interés superior del niño, sin considerar, siquiera, la opinión de éstos ${ }^{9}$.

${ }^{6}$ Corte Interamericana de Derechos Humanos, "Condición jurídica y derechos del niño", en Opinión Consultiva OC-17/02, Costa Rica, 28 de agosto de 2002, p. 595.

${ }^{7}$ Cortés (n. 1), pp. 64-70.

${ }^{8}$ Miguel Cillero, "De la tutela a las garantías: consideraciones sobre el proceso penal la justicia de adolescentes", en Revista Derecho del Niño, No 2, Santiago, 2003, pp. 53-57.

${ }^{9}$ Como ocurrió en la decisión de la Corte Suprema en el 'Caso Atala', donde los jueces de mayoría "contrabandearon" sus propias convicciones morales bajo una supuesta protección del interés superior del niño. La decisión de instancia había hecho referencia a la opinión de las niñas involucradas, mientras la Corte Suprema prefiere simplemente omitirlas. Domingo Lovera, "Razonamiento Judicial y Derechos del Niño: de ventrílocuos y marionetas", en Revista Justicia y Derechos del Niño, No 10, Bogotá, 2008, pp. 57-60. 
La referencia, entonces, es vaga e imprecisa, pero al menos existe. De hecho, y a diferencia de lo que ocurre en otras latitudes (Colombia, por caso), la Constitución Política de la República carece de referencias expresas a la situación jurídica de niños, niñas y adolescentes. Esto, sin embargo, no debiera ser óbice al desarrollo de la titularidad y ejercicio de derechos constitucionales de parte de niños y adolescentes; y parte importante de la tarea dogmática es la de sugerir construcciones coherentes que permitan, luego, revisar las decisiones judiciales.

Si la CDN innova no sólo cuando reafirma la titularidad de derechos sino que, sobre todo, cuando insiste en la autonomía de niños, niñas y 218 adolescentes para reclamar el ejercicio de esos derechos-definidos pory desde ellos-, entonces el interés superior del niño que la CDN manda asumir como consideración primordial a la que se debe atender decidiendo "medidas concernientes a los niños," se satisface en dos niveles.

\section{Titularidad}

Primero, el interés superior del niño se satisface cuando se reconoce la titularidad de derechos constitucionales. Y no podría ser de otra forma. La Constitución dispone que las personas nacen libres e iguales en dignidad y derechos (art. $1^{\circ}$ ), asegurando derechos a todas "las personas" (art. 19). Como ha señalado Rodrigo Barcia, la titularidad de derechos constitucionales es una que no se juz- ga a la luz de las reglas de capacidad patrimonial ${ }^{10}$. De hecho la CDN -y su interpretación auténtica- extiende la titularidad de derechos a todos los niños, incluso, en la etapa de infancia y preadolescencia. Así, el comentario general $\mathrm{N}^{\mathrm{T}} 7$ del Comité de Derechos del Niño de Naciones Unidas dispone:

"los niños pequeños son titulares de todos los derechos consagrados en la Convención"11,

reafirmando, como ha dicho $\mathrm{Mi}$ guel Cillero, el reconocimiento de los niños como personas humanas, atribuyéndoseles la titularidad para demandar igual respeto y protección de sus derechos ${ }^{12}$.

\section{Autonomía progresiva}

Segundo, el reconocimiento de la titularidad de derechos debe ir acompañado de una teoría de la autonomía. En caso contrario, esto es, si el interés superior del niño significa

${ }^{10}$ Rodrigo BARCIA, "Sobre la capacidad de los adolescentes para recibir la denominada píldora del día después", en Revista Chilena de Derecho Privado, $\mathrm{N}^{\circ} 7$, Santiago, diciembre 2006, pp. 139-140.

${ }^{11}$ Comité de los Derechos del Niño de Naciones Unidas, "Observación general”, $\mathrm{N}^{\mathrm{o}}$ 7, CRC/C/GC/7/Rev.1 (20 de abril de 2006).

${ }^{12}$ Miguel Cillero, "El interés superior del niño en el marco de la Convención Internacional sobre los Derechos del Niño, en Revista Justicia y Derechos del Niño, $\mathrm{N}^{\circ}$ 9, Santiago, 2007, pp. 125, 130. 
sólo reconocimiento de titularidad de derechos, pero para que se configuren y protejan desde fuera de los niños y adolescentes, el principio es irrelevante. Irrelevante, pues, habríamos llegado al mimo resultado por otro camino, sin necesidad de interés superior del niño-por ejemplo, leyendo correctamente las normas constitucionales que atribuyen titularidad de derechos a todas las personas ${ }^{13}$.

En esa línea Michael Freeman sugiere:

"[u]na teoría plausible de los derechos necesita tomar en cuenta no sólo la igualdad [de dignidad y de derechos], sino también el valor normativo de la autonomía, la idea de que las personas como tales tienen un conjunto de capacidades que les permiten tomar decisiones independientes en relación con las opciones de vida convenientes" ${ }^{\prime 1}$.

La CDN, por su parte, ordena a los Estados garantizar

"al niño que esté en condiciones de formarse un juicio propio el derecho de expresar su opinión libremente en todos los asuntos que afectan al niño, teniéndose debidamen-

${ }^{13}$ Cortés (n. 1), p. 71.

${ }^{14}$ Michael Freeman, "Tomando más en Serio los Derechos de los Niños", en Revista Derechos del Niño, Santiago, No 3-4, Santiago, 2006, p. 271. te en cuenta las opiniones del niño, en función de la edad y madurez del niño"15.

En Derecho Comparado, como se ha sugerido, el criterio que se ha impuesto es el de la autonomía progresiva, esto es, un criterio que asume que los niveles de autonomía de las decisiones de los niños varía de acuerdo con factores y circunstancias específicas de cada caso, atendiendo en especial a la edad, madurez y capacidad de comprensión de los involucrados ${ }^{16}$. A medida que avanza la edad de nuestros hijos disminuye la esfera de control que tanto el Estado y los padres tienen sobre él, abriéndose el campo a decisiones libres ${ }^{17}$.

$$
\text { 3. En fin }
$$

Por los argumentos desarrollados brevemente más arriba, es importante insistir en que el cambio que introduce la CDN confirma la titularidad de los niños y adolescentes sobre sus derechos constitucionales, por una parte, y asigna a ellos y ellas un

"rol protagónico [del que antes estaban privados] en la decisión de cómo ejercer y proteger sus derechos" 18 .

${ }^{15}$ Artículo 12.1.

${ }^{16}$ Malcolm Dodds, Family Law, London, Old Bailey Press, 2004, p. 126.

17 "Gillick v West Norfolk and Wisbech Area Health Authority", All England Reports, vol. 2, London, 1985, p. 402.

${ }^{18}$ Jaime Couso, "El niño como sujeto de derechos y la nueva justicia de familia. Interés 
De ahí que las decisiones judiciales que construyen el interés superior del niño desde fuera de éstos, es decir, sin tomar en cuenta ni su titularidad ni su ejercicio autónomo, no son otra cosa que imposiciones de lo que los jueces (los padres o el Estado) creen que va en interés de los niños, pero nunca la satisfacción de ellos.

\section{III}

La tesis no es sencilla de satisfacer. Pero como las tareas difíciles son las más gratificantes, vale la pena revisar un importante caso decido a comienzos de 2009.

Surge a propósito de las protestas estudiantiles en contra de las modificaciones propuestas a la LGE y trata sobre un estudiante de quince años, deseoso de

"prestar un servicio a la comunidad escolar y de aportar al mejoramiento de su colegio",

según asevera su madre recurriendo a su nombre ${ }^{19}$. El adolescente -señala la recurrente- lleva adelante su obra por medio de la citación a reuniones y la difusión de material relativo a las reformas propuestas a la educación pública chilena, básicamente actividades de difusión. Al

superior del niño, autonomía progresiva y derecho a ser oído", en Revista Derechos del Niño, Santiago, No 3-4, 2006, pp. 145-148.

${ }^{19}$ Corte de Apelaciones de Antofagasta, rol No 36,6 de marzo de 2009. momento de ir a pagar la renovación de la matrícula el director del colegio habría señalado que al estudiante no le preocupaban sus estudios ni respondía al perfil de la institución -el liceo "Experimental Artístico y de Aplicación de Antofagasta"- pues, estaba más interesado en desarrollar actividades políticas en el establecimiento, lo que, según el Consejo de Profesores, justificaba la cancelación de la matrícula. La recurrente reclamó la violación de los derechos a la igualdad y a la propiedad y el derecho a elegir el establecimiento de su hijo, en su caso particular.

El colegio, al evacuar el informe, confirmó la versión de la recurrente. El estudiante no se habría preocupado de sus estudios, pues

"se puede observar con un conjunto de propaganda utilizada durante todo el año, y que demuestran desarrollar inquietudes políticas partidarias más que intereses estudiantiles del nivel que cursan los alumnos de la enseñanza media" ${ }^{20}$.

Entre la propaganda partidista que menciona el recurrido, se cuentan mensajes del siguiente tenor:

"Contra la educación de mercado, contra la Loce de Pinochet y su hermana, la L.G.E. del negocio transparente de la Concertación y la Derecha.

\section{${ }^{20}$ Ibid.}


Ni Loce ni L.G.E. Luchemos contra la precarización de la educación, el trabajo y el arte. Forjemos la unidad con los trabajadores contra la precarización de la educación y la vida. Viva la unidad obrero estudiantil. Luchemos por refundar nuestros centros de alumnos y federaciones en base a la democracia directa estudiantil, delegados revocables en todo momento", entre otros $^{21}$.

La Corte de Apelaciones de Antofagasta comenzó su análisis citando el inciso $2^{\circ}$ del artículo $6^{\circ} \mathrm{de}$ la LOCE, el que dispone:

"Los establecimientos o instituciones educacionales, cuya

21 "Porque la P.S.U. es un filtro de clase para los colegios públicos y privados. Luchemos por el acceso irrestricto a la universidad. No a la P.S.U. Contra la precarización de nuestra educación artística, forjemos un comité de Artes y Cultura. Por los derechos de la mujer y las minorías sexuales. Luchemos contra la criminalización de las luchas contra los trabajadores, los sectores oprimidos, los jóvenes, basta de represión a los que luchan". Además, reprocha otras actividades el estudiante: "postuló al cargo de Presidente del Centro de Alumnos del Liceo, encabezando una lista denominada mayo 68, en homenaje a los movimientos libertarios ocurridos en París en mayo de 1968. Acompaña propaganda (documento $\mathrm{N}^{\mathrm{O}} 1$ denominada Vota Lista 2 donde destaca la mano empuñada que afirma una llave-lápiz. Dicho mensaje simbólico se complementa con otra propaganda (documento $\mathrm{N}^{\mathrm{o}}$ 2)....”. Corte de Apelaciones... (n. 19). enseñanza sea reconocida oficialmente, no podrán orientarse a propagar tendencia político partidista alguna" ${ }^{22}$.

El error de la Corte estriba en el hecho de no comprender que dicha disposición está destinada a la configuración de los proyectos educativos de los establecimientos educacionales, pero que no puede imponerse a los estudiantes, por lo que esa disposición no resuelve el caso presentado $^{23}$. Y como no lo hace, fija su atención en el reglamento interno del colegio, sin analizar la amplitud de las causales ni los procedimientos contenidos en él, concluyendo que:

"no se advierte que hubiera existido de parte del Director del Liceo Experimental Artístico, algún acto u omisión arbitrario o ilegal que conculque alguna de las garantías constitucionales a que se alude" ${ }^{24}$.

La Corte Suprema revoca la decisión $^{25}$. Sosteniendo, para ello, que no hay elementos que permitan probar

${ }^{22}$ Ley $\mathrm{N}^{\mathrm{o}} 18.962$ (Diario Oficial, $10 \mathrm{de}$ marzo de 1990).

${ }^{23}$ Incluso, resulta complejo afirmar que esas limitaciones puedan aplicarse a los profesores, siendo claro que no se les aplican ni a estudiantes (pues no va dirigida a ellos) ni a profesores, fuera del establecimiento. Eric BARENDT, Freedom of Speech, London-New York, Oxford University Press, 2005, pp. 498-500.

${ }^{24}$ Corte de Apelaciones... (n. 19), cons. 3,4 y 5 .

${ }^{25}$ Corte Suprema, rol No $1.740,23$ de abril de 2009 . 
la existencia de actos de indisciplina de parte del estudiante, y que:

"la [sola] circunstancia de que el 'Manual de Convivencia Escolar' del colegio recurrido autorice la caducidad de la matrícula en casos de suma gravedad luego de oír al consejo de profesores de curso o al consejo general de profesores y que el contrato de prestación de servicios educacionales fue suscrito sólo por el año lectivo 2008, no son razones jurídicas que puedan justificar el cese de la relación educativa" ${ }^{26}$.

Enseguida, califica las acciones del estudiante como manifestaciones de la libertad de expresión que la Constitución asegura a todas las personas, señalando que la única motivación del colegio -analizadas las excelentes calificaciones y asistencia del estudiante-fue contravenir dicha libertad $^{27}$. Esa limitación, agregó, es arbitraria, pues

"no es razonable expulsar de alguna comunidad a una persona a causa de que ésta sustente ideas que se califican de contrarias a los valores que reconoce la entidad, entre otras razones, porque se la excluye no obstante el derecho de expresión que le asiste" ${ }^{28}$.

\footnotetext{
${ }^{26}$ Corte de Apelaciones... (n. 19), cons. 2.

${ }^{27}$ Corte de Apelaciones... (n. 19), cons. 3.

${ }^{28}$ Ibid.
}

Junto con invocar la Constitución, se refiere a las disposiciones sobre libertad de expresión de la CDN para concluir, en forma notable, configurando el interés superior del niño desde el adolescente, como uno que se configura, desarrolla y fortalece con su intervención -en línea con lo que he señalado, más arriba, es una correcta interpretación del principio en cuestión-. Así, argumentó que

"no se advierte ningún motivo que justifique el proceder del establecimiento educacional, puesto que es evidente que no se tuvo en cuenta razones relacionadas con el interés superior del niño, en la especie con la preservación y fortalecimiento de su desarrollo formativo, sino únicamente la negativa valoración de sus posiciones" 29 .

Las referencias son crípticas, quizá, pero relevantes para el objetivo que se persigue. La Corte $-\mathrm{a}$ diferencia de lo que hizo en el caso 'Atala' ${ }^{30}$ - prefiere entender que el interés superior del niño es uno que no puede construirse legítimamente desde el interés de los jueces o desde el interés del colegio (que no comparte sus ideas), sino, cosa distinta, que se trata de un criterio primordial al que debe atenderse para decidir casos en que hay niños y adolescen-

${ }^{29}$ Corte de Apelaciones... (n. 19), cons. 4 (el destacado me pertenece).

${ }^{30}$ Lovera (n. 9). 
tes involucrados, y que se construye con su propia participación. Por eso, destaca, de manera acertada, que el interés superior del niño tiene relación directa con su procedimiento formativo, un procedimiento que debe permitir no sólo reclamar la titularidad sobre derechos sino, también, el ejercicio autónomo (fortalecimiento de su desarrollo formativo), aun cuando las instancias de control estén en desacuerdo con la forma en que se desarrolla ese ejercicio.

Como se aprecia, la Corte Suprema avanza un argumento que no es común cuando se enfrenta a casos de cancelaciones de matrícula. Acá, está dispuesta a aceptar el carácter expresivo de las actividades desarrolladas por el estudiante, agregando, además,

i) que si bien existe un reglamento escolar,

ii) no es irrelevante la amplitud de sus causales ni

iii) la discrecionalidad de procedimientos (cuando los hay) y decisiones que se adoptan a su amparo.

En este caso, en cambio -y en línea con el argumento sostenido en Derecho Comparado ${ }^{31}$ - argumenta sobre la base de la especial protección que posee el discurso de crítica política (y el discurso político, en general), por una parte, y la titularidad de derechos que se reconoce al adolescente, junto a un ejercicio autónomo, por otra. Esto no quiere decir que los demás discursos carezcan de protección en

${ }^{31}$ Barendt (n. 23), pp. 496-497. el especial contexto educacional, pues, como se ha señalado, niños y adolescentes no dejan sus derechos constitucionales en la puerta de entrada de los establecimientos. Pero sí significa que, a diferencia del discurso político (cuya restricción goza de una presunción de inconstitucionalidad), los esfuerzos argumentativos de quienes reclaman la libertad de expresión para otros tipos de discurso serán más exigentes, y derechamente inconstitucionales cuando esas restricciones se impongan en virtud de la supuesta protección del proceso formativo del adolescente, que la forma inadecuada de comprender el interés superior del niño.

IV

Las implicancias de esta decisión de la Corte Suprema en el Derecho de Familia son redundantes, por una parte, y muy relevantes, por otra. Redundantes porque -como vimos más arriba- la consideración a los intereses del niño ya se encuentra legalmente consagrada, es decir, las disposiciones del Código Civil y las de la ley que regula los tribunales de familia, contienen referencias expresas al interés superior del niño como consideración primordial (y principio rector) a la que se debe atender, decidiendo "medidas concernientes a los niños" - para recuperar el lenguaje de la CDN. La experiencia nos ha enseñado, sin embargo, que estas referencias no son suficientes- ni operan, en verdad, como límite a la 
discrecionalidad de las autoridades. Como ya vimos, es fácil para los jueces imponer sus propias concepciones del bienestar al niño y adolescente, y disfrazarlas en nombre del interés superior del niño ${ }^{32}$. Por otra parte, si bien en el contexto del Derecho de Familia puede tratarse de referencias consagradas en la ley, y en ese sentido redundantes, en el contexto de recursos de protección, decidiendo medidas concernientes a los niños, se trata de estándares que se utilizan (cuando se utilizan) de manera aleatoria y dependiendo de la voluntad del juez de turno.

Con todo, y pese a la redundancia al menos enunciativa, la sentencia de la Corte Suprema es muy relevante para la jurisdicción de familia 224 en tanto contribuye, en línea con los mandatos de la CDN, ha construir una correcta interpretación del interés superior del niño. Como señalamos antes, una correcta interpretación del interés superior del niño, esto es, una que dota a dicho principio de utilidad, es aquélla que no se detiene en el reconocimiento de la titularidad de derechos -caso

${ }^{32}$ Ésta es, en parte, una de las razones que Michael Freeman esgrime para criticar la forma en que los tribunales ingleses han comenzado a apartarse de la decisión en Gillick (n. 17), reclamando-los tribunales-jurisdicción inherente para revocar las decisiones declaradas de niños y adolescentes competentes (de acuerdo con Gillick), argumentando la satisfacción del propio bienestar de niños y adolescentes (!). Michael Freeman, "Rethinking Gillick", in Internacional Journal of Children's Rights, $\mathrm{N}^{\mathrm{o}}$ 13, Buffalo 2005. en el cual el principio es irrelevantesino que una que avanza a construir la posibilidad de adoptar decisiones autónomas a partir de esa titularidad. Como se infiere de la decisión de la Corte en el caso en comento, el interés superior del niño adquiere fuerza en la medida que se reconoce que el niño y adolescente puede adoptar autónomamente sus decisiones porque se entiende que son parte constitutiva de su proceso formativo, uno que, concluido, los dotará de plena autonomía. Si esas decisiones -sobre todo en áreas tan sensibles como la libertad de expresión- son limitadas o, bien, prohibidas desde algún otro lugar (sea desde sus padres, desde sus profesores, desde las autoridades educacionales o desde los jueces y legisladores ${ }^{33}$ ), entonces es posible argumentar que no sólo el ejercicio autónomo de derechos es el que se afecta sino, también, la titularidad de los mismos. Por lo tanto el principio siquiera sirve para reforzar esa titularidad, que, además, podría haberse reclamado desde otro lado (desde la Constitución). Todo lo

${ }^{33}$ Mientras escribimos esta nota se discute en el Congreso un proyecto de ley destinado, entre otras cosas, a permitir la consejería sobre regulación de la fertilidad en términos confidenciales, incluidos adolescentes mayores de catorce años. Parlamentarios de la Alianza por Chile ya han señalado que presentarán una indicación alterando la propuesta, e introduciendo el deber de los adolescentes de contar con el consentimiento de sus padres para poder optar a las consejerías, en abierta contravención a las normas de la CDN y la vida privada. Véase, Mensaje $\mathrm{N}^{\mathrm{O}} 667-257,30$ de junio de 2009. 
contrario; termina dejando al niño y al adolescente en una situación todavía más precaria, de vuelta a un sistema tutelar y de protección.

\section{Bibliografía}

BARCIA, Rodrigo, "Sobre la capacidad de los adolescentes para recibir la denominada píldora del día después", en Revista Chilena de Derecho Privado, ${ }^{\circ}$ 7, Santiago, diciembre 2006.

Barendt, Eric, Freedom of Speech, London-New York, Oxford University Press, 2005.

Cillero, Miguel, "De la tutela a las garantías: consideraciones sobre el proceso penal la justicia de adolescentes", en Revista Derecho del Niño, No 2, Santiago, 2003.

Miguel Cillero, "El interés superior del niño en el marco de la Convención Internacional sobre los Derechos del Niño, en Revista Justicia y Derechos del Niño, No 9, Santiago, 2007.

Comité de los Derechos del NiÑo de NaCiOnes Unidas, “Observación general”, No 7, CRC/C/GC/7/Rev.1 (20 de abril de 2006).

Committee on the Rights of the Child: Chile, "Concluding Observations of the Committee on the Rights of the Child: Chile", CRC/C/15/add.22. (25 de abril de 1994).

Corte Interamericana de Derechos Humanos, "Condición jurídica y derechos del niño", en Opinión Consultiva OC-17/02, Costa Rica, 28 de agosto de 2002.

CORTÉs, Julio, "Acerca del principio del interés superior del niño", en Julio Cortes, Consuelo Contreras, Infancia y Derechos Humanos: discurso, realidad y perspectivas, Santiago, Corporación OPCIÓN, 2001.

Corte Europea de Derechos Humanos, "Yousef v The Netherlands", in $\mathrm{Fa}^{-}$ mily Law Reports, London, 2003.

Couso, Jaime, "El niño como sujeto de derechos y la nueva justicia de familia. Interés superior del niño, autonomía progresiva y derecho a ser oído", en Revista Derechos del Niño, Santiago, No 3-4, 2006.

Dodds, Malcolm, Family Law, London, Old Bailey Press, 2004.

Freeman, Michael, "Rethinking Gillick", in Internacional Journal of Children's Rights, № 13, Buffalo 2005.

Freeman, Michael, "Tomando más en Serio los Derechos de los Niños", en Revista Derechos del Niño, Santiago, $\mathrm{N}^{\circ}$ 3-4, Santiago, 2006.

"Gillick v West Norfolk and Wisbech Area Health Authority", All England Reports, vol. 2, London, 1985.

Lovera, Domingo, "Razonamiento judicial y Derechos del Niño: de ventrílocuos y marionetas", en Revista Justicia y Derechos del Niño, $\mathrm{N}^{\circ} 10$, Bogotá, 2008.. 